\title{
El agrupamiento de textos en la escuela elemental ${ }^{*}$ Grouper des textes à l'école élémentaire*
}

\author{
Jacques David ${ }^{*}$ \\ jak.david@orange.fr \\ Annie Perrot ${ }^{* *}$ \\ martin@caen.iufm.fr \\ Serge Martin** \\ I.U.F.M de Versailles- Centre de Cergy
}

\section{Presentación}

$66 \begin{aligned} & \text { grupar textos" en la escue- } \\ & \text { la elemental evoca lo que } \\ & \text { se hacía antes. ¿Por qué no? }\end{aligned}$ Después de decenas de años, tanto los manuales de lectura como los de francés (de manera integrada), ofrecen una organización temática conformada por: fragmentos de textos agrupados bajo la consigna de palabrastemas (el mar, el otoño...). Tipos y géneros de textos se mezclan sin que las nociones y los problemas particulares de lectura y escritura allí implicados se articulen bajo un campo temático. Esta aproximación permanece implícita y nada se problematiza, ya que todo parece ir bien para los alumnos y el maestro, la lectura de cada texto queda encerrada en ella misma.

La lectura de al menos dos textos a la vez es realmente novedosa puesto que cada alumno practica cotidianamente una lectura extracurricular: sus ojos raramente se satisfacen con un solo fragmento escogido, y la lectura sobrepasa siempre la selección de un escrito a otro. Al explicar la intertextualidad y la transtextualidad, se reflexiona sobre las relaciones entre los textos, pero sobre todo, se ponen al día las relaciones que se tejen entre las lecturas simultáneas o sucesivas de los alumnos.

* Recibido: 21 de abril de 2009 / Aceptado: 15 de mayo de 2009.

** Texto original en francés "Grouper des textes à l'école élémentaire", traducido de Le Français aujourd'hui. Número especial: Enseigner la littérature de jeunesse (Enseñanza de la literatura juvenil), Paris, édition Armand Colin, diciembre de 2008. Traducido por Blanca Bojacá y Raquel Pinilla, Grupo de Investigación Lenguaje, Cultura e Identidad, Universidad Distrital Francisco José de Caldas.

Ph. D. en Ciencias del Lenguaje de la Universidad René Descartes, Paris 5. Profesor titular de la Universidad de Cergy Pontoise. Editor de la revista Le Français Aujourd'hui. jak.david@orange.fr

** Profesor titular del Instituto Universitario de Formación de Maestros (IUFM) de la Baja Normandía. serge. martin@caen.iufm.fr

${ }^{* * *}$ Formadora en literatura juvenil. Institut International Charles Perrault. 
Nuestras propuestas, concernientes al ciclo de profundización ${ }^{1}-\mathrm{y}$ por qué no también al colegio-, pretenden modificar los ejercicios tradicionales de lectura (cuestionamientos al texto y otras pruebas). Nociones como personaje, variaciones textuales, motivo narrativo y esquema simbólico nos permiten articular diferentes aproximaciones lingüísticas y culturales para las actividades de lectura y escritura.

\section{Nuestro proyecto se orienta más hacia la búsqueda de especificidades bajo la aparente similitud, que a encontrar los puntos comunes, inevitablemente muy generales, en una serie de textos.}

\section{Entrar en la novela a través de los personajes}

Jacques David

Las novelas y las novelas cortas que hemos reagrupado tienen como rasgo común haber sido construidas a partir de los hechos y las acciones de un personaje no necesariamente único, pero al menos central. Este puede ser un niño de aproximadamente la misma edad (esto cuando les damos los textos para leer) que los lectores destinatarios de los textos. Estas narraciones pertenecen a una tradición novelesca presente en gran parte de los relatos de niños característicos de la literatura escolar (E1 tour de Francia realizado por dos niños) o que la escuela se ha apropiado progresivamente. Mostramos de esta manera que la mayoría de los textos de lectura seleccionados se relacionan con este género narrativo: Habia una vez un paje - CE2 (Mathan), representa cerca del $45 \%$ de los relatos o de frag-

\footnotetext{
1 En el sistema educativo francés el ciclo de profundización corresponde en nuestro sistema educativo a la media, es decir, grados 10 y 11 aproximadamente. El collège equivale a la básica secundaria, grados sexto a noveno.
}

mentos propuestos especialmente junto con $E l$ gran viaje de Alexandre Tolpe de M. Grimaud; Es para leer-CM1 (Hachette), constituye cerca del $70 \%$, con, claro está, Alicia en el país de la maravillas y también con Camilo o el niño doble de Vercors. Por otra parte, basta con recorrer los títulos de múltiples colecciones de ediciones para la juventud: Ratón negro o Rosa, de Syros; Benjamin y Cadet de Gallimard; Me gusta leer, edición Bayard... para constatar la importancia de este género y su abundancia en las bibliotecas de las aulas o de las escuelas.

Por consiguiente, podríamos proponer múltiples agrupamientos de textos (en adelante AT) que tendrían por objeto de estudio en su totalidad o en parte la problemática relacionada con los "relatos de niños". Si nos limitamos solo a las características del personaje principal, tendríamos igualmente motivo para numerosas combinaciones. La primera sería, sin ninguna duda, la de responder a las dificultades de lectura, a menudo insospechadas, de nuestros alumnos, a saber: las distinciones entre personajes $y$ personas y, más precisamente, la identificación de los rasgos humanos / no humanos o animados / inanimados en la introducción y la cualificación de unos y de otros.

Sin embargo, nuestro proyecto se orienta más hacia la búsqueda de especificidades bajo la aparente similitud, que a encontrar los puntos comunes, inevitablemente muy generales, en una serie de textos. Ganamos más al trabajar la comparación bajo el ángulo de las diferencias que de las similitudes. De una parte, los niños captan más fácilmente aquello que "es diferente" de lo que es "parecido". De otra parte, este tipo de análisis produce mayores efectos, bien sea en la recepción al momento de interpretar los textos, o en la producción durante las actividades orientadas a la redacción.

Por esta razón en el presente estudio, llevado a cabo con alumnos del ciclo III (CE2, CM1, CM2) ${ }^{2}$, hemos centrado nuestro análisis sobre los diferentes modos de "la entrada en escena"

\footnotetext{
2 Corresponde a los grados tercero, cuarto y quinto de básica primaria.
} 
del personaje principal. Para hacerlo, los niños tuvieron que leer los seis textos siguientes:

- La Maison vide (La casa vacía, en adelante, La CV), de Cl. Gutman, Gallimard "Page blanche", 1989.

- La Croix du Sud (La cruz del sur, en adelante, La C del S), de H. Jaouen, Syros, (Los ratones más negros), 1988.

- Mondo (en adelante Md).

- La Montagne du dieu vivant (La montaña del dios viviente, en adelante La M del DV).

- Peuple du ciel (Pueblo del cielo, en adelante $\mathrm{PC})$.

- Les Bergers (Los pastores, en adelante Los Ps), cuatro novelas de la colección Mondo et autres histoires (Mondo y otras historias), de J. M. G. Le Clézio, Gallimard, "Folio”, 1978.

\section{Los estatus de autor, de narrador y de personaje}

La mayor parte del tiempo es conveniente identificar claramente los diferentes polos en la organización de los relatos, principalmente, con los alumnos poco familiarizados con estas lecturas. De esta manera, en la CV, el personaje principal y el narrador se confunden e identifican bajo la misma denominación: David. Este actúa, habla y piensa en primera persona. De otra parte, como no se trata de una autobiografía, el autor y el narrador-personaje principal no pueden amalgamarse.

Por el contrario, en cada una de las cuatro novelas seleccionadas de Mondo y otras historias, el autor, el narrador y el personaje central se diferencian muy bien a lo largo del texto. Cada uno de los personajes está generalmente denominado y en parte definido desde las primeras líneas: "nadie habría podido decir de dónde venía Mondo. Él había llegado un día...” (primera línea de Md), "el monte Reydarbamur estaba a la derecha del camino y Jon sólo lo veía a él...” (cuatro primeras líneas de la M del DV), "Crucesita quería sobre todo hacer esto: ella iba..." (Primera línea de PC).

Finalmente, aunque las focalizaciones permanecen homogéneas en estos relatos enfocándose o en el narrador o en el personaje principal, no ocurre igual en La C del S ya que el autor, el narrador y el personaje central (Stéphane) se presentan bien diferenciados. Solamente a partir del capítulo 6, al comienzo de la segunda parte, en el momento en que el relato avanza y retrocede, es que el narrador toma forma de personaje y se encuentra directamente identificado como Aurélie (señalado en el título mismo de esta segunda parte) y es introducido en un discurso en primera persona. "Cuando Stéphane timbró en nuestra casa... él tuvo la suerte de encontrarme en la casa: papá, mamá y yo, acabábamos de entrar...". Este cambio de estatus del narrador, indeterminado en la primera parte de la novela, después identificado bajo los rasgos de una amiga de Stéphane, debe ser analizado por los alumnos aunque con tropiezos a menudo sorprendentes frente a la interpretación de las relaciones entre los personajes.

Un primer estudio de estos textos entonces tiene por objeto llamar la atención sobre los múltiples índices que permiten identificar las diferentes instancias de su escritura. La ausencia de análisis sobre esta dimensión del relato constituye a menudo un obstáculo para su comprensión. Esta necesita tanto de la interpretación literal del texto con sus bruscos cambios de focalización (como por ejemplo en La C del S) como de la búsqueda de informaciones en el contexto que permitan delimitar el estatus de cada uno y especialmente del narrador (como en la $\mathrm{CV}$, donde el autor no cuenta su propia infancia, sino que retrata la de un niño ficticio, David, escogiendo para su narración la primera persona).

\section{Denominación y cualificación de los personajes}

Un segundo estudio, centrado esta vez en el personaje principal, se ha realizado para permitir a los estudiantes poner de relieve los índices que sirven, de una parte, para la denominación y, de otra parte, para definirlo o cualificarlo.

De esta manera tenemos en nuestro agrupamiento de textos diferentes modalidades para la introducción del personaje, lo que exige lecturas y a menudo análisis puntuales, más o menos complejos. En La C del S, la presentación de Stéphane es perfectamente explícita: "Es normal que se llame Stéphane, que tenga doce años, que sea un muchacho gentil, sea el primero de su clase, que le guste la lectura y el cine..." . No existe 
ambigüedad potencial en cuanto a la identidad del personaje, y todas las informaciones que permiten situarlo se proporcionan desde el comienzo de la novela. Sucede lo mismo en Md, cuyo personaje central se encuentra igualmente descrito desde el primer párrafo: "Era un muchacho de unos diez años, con una cara redonda y tranquila, de bellos ojos negros un poco oblicuos... cabellos castaños, no se sabía nada de su familia, ni de su casa...".

Por el contario en Los Ps, es necesario esperar hasta la quinta página para ver aparecer un personaje humano que no es nombrado, sino simplemente evocado mediante una serie de indefinidos: "Alguien llegaba del largo sendero... Era un joven vestido como las personas del pueblo... traía sobre el hombro una chaqueta de lino un poco arrugada...”. En esta novela, parece que el personaje se despoja progresivamente de un decorado natural anteriormente descrito en cuatro páginas completas. La denominación indefinida (alguien... un joven...) aumenta el carácter impresionista de la descripción de los lugares. Es dos páginas más adelante, con la irrupción en el relato de cuatro muchachitos, cuando descubrimos el nombre del personaje: "Con una voz un poco ronca el joven dice: -me llamo Gaspard". Un procedimiento análogo es utilizado en la novela de C. Gutman, la CV. Sin embargo, esta vez se hace un empleo regular y previo de la primera persona: "yo enrollé mi pijama en mi brazo. Subí dos pisos... después (papá) se volvió hacia mí: - La guerra, tú sabes David, es una gran cabronada..., al ser introducido directamente de esta manera en la evocación de una escena de segundo plano, el lector es conducido a destacar una serie de informaciones que cualifican al narrador-personaje central antes de conocer el nombre de David.

Aunque sea anterior a la descripción-cualificación (La C del S) o posterior a ella (Los Ps y $\mathrm{La} C V$ ), la denominación del personaje principal nunca es ambigua; como en el caso de Stéphane, y de Gaspar y David en el segundo caso. Sin embargo, no debemos considerar esto mismo para los otros textos. Así, en Md o en la La M del DV, los nombres de Mondo y Jon no se corresponden, de manera tan evidente, con el universo de referencia de los estudiantes. Si Mondo puede ser identificado sin dificultades y desde las primeras líneas como un joven, a la inversa, Jon solamente es identificado nueve líneas más adelante como un personaje masculino (él había dejado su bicicleta nueva...") y relativamente joven -o por lo menos no adultopuesto que iba a la escuela ("Él se iba a pie para la escuela"). Por las mismas razones Crucecita, en PC, es inmediatamente identificada como personaje femenino ("Crucecita amaba sobre todo hacer esto: ella iba...") sin que se tenga, sin embargo, una indicación precisa sobre su edad.

En definitiva, conviene analizar precisamente los procedimientos de denominación empleados por el autor y, aún más, identificar los elementos presentes o implícitos que aseguran la cualificación-descripción de los personajes ${ }^{3}$. El grado de precisión introducido aquí y en su presentación determina, en gran parte, la comprensión de los hechos narrados y, en general, del relato en su conjunto.

\section{Designación y referencia a los personajes}

Más allá de los dos estudios precedentes -que hacen referencia a nociones de semiótica narrativa- proponemos otro análisis, ligado a hechos de textualidad y más específicamente lingüísticos.

Muchos trabajos ya han descrito las dificultades de la lectura asociadas a las modali-

\footnotetext{
3 Con el fin de prolongar la reflexión y encontrar propuestas de actividades complementarias, remitimos a los lectores a publicaciones como Reuter (1987 y 1991).
} 
dades de designación y de referenciación de los actantes de un texto (cfr. especialmente el artículo de M. Laparra, el de Masseron y Schnedecker en Pratiques 60, 1988, y David, Martin y Perrot en Le francais Aujourd 'bui 86, 1986). Es la razón por la cual en el agrupamiento de textos aquí escogido, nos parece determinante un estudio fino de estos fenómenos. Conviene, en efecto, ayudar a los alumnos a realizar selectivamente sus lecturas sobre estos componentes complejos de localizar, es decir, las cadenas de correferencia.

Podemos, por consiguiente, proponerles que den a conocer a lo largo de todos los textos -y de manera transversal para compararlos- los diferentes elementos y procedimientos de designación y de referencia del personaje principal: expresiones como hijo mayor, adorable, muchachito, que reenvían a Stéphane en La C del S, o aquellas que se refieren a David en La CV, bijo, único niño, pequeño, pobre niño... Estos últimos son más difíciles de ubicar porque están exclusivamente insertados en las partes dialogadas, de manera que el relato se construye en primera persona, desde el punto de vista de este personaje.

Igualmente, debemos rectificar las numerosas incomprensiones asociadas al empleo de categorías de unidades gramaticales que reenvían de manera menos explícita a estos personajes. Por ejemplo, el conjunto de determinantes que acompañan las múltiples referencias a Stéphane: "su hijo mayor... el adorable, el muchachito", o para David como "mi hijo... mi niño...", incluso la ausencia de toda determinación: "pequeño... pobre niño...”. En la tradición gramatical escolar estas marcas son definidas, esencialmente, en función de la relación ortográfica que mantienen con los otros elementos del sintagma (en tanto contienen las indicaciones de género y de número). Solamente son consideradas cuando se hace en una relación interfrástica, es decir, como elementos de una cadena anafórica precisa, en la ocurrencia del personaje principal.

En la misma perspectiva, es importante que los alumnos establezcan los vínculos de cohesión que mantienen la denominación y las diferentes designaciones de este personaje con las múltiples referencias pronominales a las que se asocian. De esta manera, en la novela de Le
Clézio, Los Ps, habíamos señalado la complejidad del modo de designación-denominación del personaje central Gaspard. Primero que todo es introducido por sintagmas indefinidos "alguien... un joven...", después se retoma como "el muchacho, el joven" y, finalmente, dos páginas más adelante se denomina "Gaspard". A las dificultades ligadas a esta inversión del procedimiento de denominación-designación se agregan aquellas inherentes al empleo repetido del pronombre "el". De hecho, muchos alumnos no comprendieron, en la inmediatez de la primera lectura, que los elementos de referencia precedían a la denominación explícita del personaje y que era conveniente, por tanto, guardar en la memoria las diferentes cualidades y los hechos sucesivamente asociados a los indefinidos "un joven...", "él” para aplicarlos enseguida y retrospectivamente a Gaspard.

Igualmente, vemos sobre este ejemplo que las descripciones gramaticales tradicionales no pueden dar cuenta de tales fenómenos de textualidad. Frente a la necesidad de identificar de manera precisa las operaciones fallidas en nuestros alumnos, no podemos contentarnos con explicaciones superficiales que solamente solucionarían problemas ortográficos. De hecho, ¿qué hacer con las reglas de concordancia y de análisis en términos de las relaciones "sujeto-verbo-objeto" en la interpretación de textos largos, en la ocurrencia, la localización y el dominio de cadenas de correferencia? Es necesario hacer un llamado a otros niveles de explicación lingüística, a menudo menos complejos de aprehender por los estudiantes y generalmente más eficaces, para el mejoramiento de las competencias tanto de lectura como de escritura.

\section{Del alfabeto a la novela: algunas propuestas de agrupamiento de textos}

Annie Perrot

La primera fórmula de agrupamiento de textos que nos viene naturalmente a la mente es proporcionada por la práctica muy en boga de la reescritura en la literatura para jóvenes, hasta el punto de constituirse casi en un nuevo género. 
No es de extrañarse, por tanto, que ubiquemos como $\mathrm{ABC}$ de este género, si así pudiera decirse, el ejemplo particularmente brillante que sigue.

De A Apple pie, de Kate Greenaway (1886), con reedición de Castle Books, 1979 y Hachette, 1986, interpretación de J. Girardin: Historia de un pastel de manzanas), a Drôle d'alphabet, ou les aventura d'une tarte aux pommes, de Agnes Rosenstielh (1977), las analogías de un circuito alfabético "se hacen evidentes, a lo largo de los saltos respectivamente efectuados por los dos postres tradicionales: en Inglaterra el 'apple pie' y en Francia 'la tarte aux pommes', ambos implicados en el relato de un recorrido humorístico".

Los parecidos estéticos del tratamiento iconográfico de las dos obras (finura del trazo, sugerencia de movimiento, cierto uso de los colores pastel y del blanco en las ilustraciones finales de los dos alfabetos: " $U V W X Y Z$ Todas obtuvieron una gran tajada y se fueron a la cama", en Greenaway, " $U V W X Y$ la cortan, la comen y se van a la cama") no le quitan nada a los aportes multiformes de la última obra.

Su trabajo creador introduce en particular una lógica más clara que en la obra precedente; deja escuchar, bajo un tono humorístico y burlesco muy personal, voces infantiles enmarcadas en globos y también diversifica tanto el dibujo de las actitudes como los juegos de palabras.

\section{llustración de un mito sobre los orígenes y reescrituras paródicas}

Las siguientes tres obras cuentan, por medio de texto e imagen, la historia del Arca de Noé:

1. L'Arche de Noé, por G. Clavigny, ilustración de O'Galop (1867-1946). 1978).

2. L'Arche de Noé, por P. Spier (1977,

3. Les Rêves de Noé : Escale à Nerw-York (1989).

Las tres obras transmiten un mito bajo dos perspectivas diferentes. Pese a su título, la reunión de los tres textos no responde solamente a criterios de orden temático.

Primero tuvimos en cuenta el álbum de $\mathrm{P}$. Spier y después agrupamos por otro lado los de Clavigny / O'Galop y el de Boucher porque nos parece que presentan convergencias que se imponen a primera vista.

En la edición en lengua francesa, la obra de Spier se ubicó deliberadamente bajo el signo de la reescritura del relato bíblico, comenzando por un texto poético de J. H. Potier, "a partir de un poema de Jacob Revius (1586-1658)". Una enumeración de animales del Arca, riguroso acá, se distancia ligeramente de su modelo bíblico por un tinte de humor, debido al ritmo del texto y a sus aproximaciones insólitas:

... el mono y su mona, la mosca, la libélula

... ibis y mariquita, jirafa y langosta;

Perezoso y oso hormiguero, boa y tórtola de todos los animales, un macho y una hembra.

Así, Dios protegió a aquellos que había creado.

¡Hurra! ¡Aleluya! Sea alabado el Señor ${ }^{4}$.

A este poema le sigue un relato en imágenes, muy rimado por el grafismo, el corte de las viñetas y los grabados, la alternancia de los planos y de los ángulos desde los que se asumen los puntos de vista, muy cercano al relato bíblico por el desarrollo general de la historia, aunque en la narración gráfica contiene toques humorísticos en la representación muy detallada y familiar de los animales del Arca. Esta selección, la finura y la animación del trazo, por demás bastante personales de Spier, evocan a veces el estilo de O'Galop.

Pero si el trabajo de Spier no permite una fácil clasificación en las categorías de G. Genette (1982) como pastiche, como pastiche satírico, o como plagio, por el contrario, en el álbum de Boucher se trata de una parodia del viaje de Noé en la que se reconocen de manera sorprendente los rasgos del caricaturista O'Galop.

\footnotetext{
4 Texto original: ... le singe et sa guenon, la mouche, le fourmilion ...

ibis et coccinelle, girafe et sauterelle,

${ }^{\text {do }}$ do et fourmilier, boa et tourterelle ;

de tous les animaux, un mâle, une femelle.

${ }^{A i} n s i$ Dieu protégea ceux qu'il avait créés.

${ }^{\text {Ho } u r r a ! ~ a l l e ́ l u i a ~ ! ~ l e ~ S e i g n e u r ~ s o i t ~ l o u e ́ ~ ! ~}$
} 
Los primeros, Glavigny y O'Galop, realizaron un cambio de contexto y un desplazamiento temporal. El viaje del Arca está tratado por ellos como un crucero de lujo en algunos grabados a color en los que se asiste a la recepción que Noé y la Señora Noé ofrecen a las bestias para mantenerlas de buen humor en el Arca y "enseñarles a los monos a comportarse bien en el mundo".

Se aprovecha la ocasión para que el dibujante O'Galop haga desfilar las parejas de animales disfrazadas de burgueses mundanos y a veces panzudos, con trajes de cola, abanicos de pluma de avestruz, collares de perla, diademas o sombreros. Muchos de estos detalles de la vestimenta fueron retomados por Boucher con una sorprendente similitud, traducida a un cromatismo análogo: rojos, verdes, azules, colores vivos y suaves, rodeados de un trazo negro muy fino en los dos ilustradores: nervioso y dinámico en O'Galop, más dulce y redondo en Boucher. Una perspectiva análoga de travestismo burlesco se reitera durante el sueño de Noé, con motivo del crucero de lujo en el curso del cual los animales caricaturizados se pelean entre sí, y al cual se agrega una "escala en Nueva York". Es la ocasión para que la ilustradora pasee a los animales del Arca por Nueva York, en una magnífica construcción cromática y gráfica.

\section{Existe otra serie de variaciones} paródicas que se relacionan con el "travestismo burlesco" -según la terminología de Genette-que se puede desarrollar según la modificación, aún más emblemática, de un elemento de la vestimenta del héroe.

El listado detallado del menú nos va a permitir jugar con las interferencias en la ilustración. C. A. Parmegiani (1989: 190) resaltó una alusión a Babar, perceptible en el vestido verde con el que O'Galop vistió al elefante y con la cachucha a cuadros verde y crema con la que cubrió su cabeza. Por otro lado, en la Escala en Nueva York el vestido completo del elefante que pinta Boucher también luce cuadros verde y crema, nuevamente como un guiño dirigido al Babar de O'Galop.

\section{Cuentos y parodia: otra vez Caperucita Roja}

Existe otra serie de variaciones paródicas que se relacionan con el "travestismo burlesco" -según la terminología de Genette- que se puede desarrollar según la modificación, aún más emblemática, de un elemento de la vestimenta del héroe, como en Caperucita Roja. Es el caso de Petit Chaperon Bleu Marine en Contes à l'envers de B. Moissard, ilustrado en blanco y negro por P. Dumas $(1977,1989)$, donde los autores hacen variar también la época con las modificaciones que esto implica en el universo de la heroína y en el registro de la escritura (ver al respecto dos álbumes: Caperucita Roja de J. Marshell (1987, 1989), y Caperucita Roja, de T. Ross $(1978,1980)$. También está el caso de Petit Chaperon Vert de G. Solotareff y Nadja (1989). Según Moissard et Solotareff, se trata más bien de juegos de reescritura, un travestismo del primer texto, "fundador", conocido universalmente, juega el rol de un mito en el imaginario colectivo. En el álbum de Caperucita Verde, el "travestismo" se torna más amplio que en los otros. No solamente aparecen varias Caperucitas (una Amarilla, y la Roja de la tradición, ligeramente variada) sino que el color verde lucido por la heroína que la protege de la codicia del lobo, conlleva una modificación de su rol: de víctima, ella se convierte en investigadora que intenta auxiliar a la Caperucita Roja, detestable en este relato. El final del cuento cae en un principio lúdico, la Caperucita Roja, que ya era bastante insolente, es declarada mentirosa por atreverse a contar la inverosímil historia de Caperucita Roja (de Grimm).

El ejercicio, siempre formal por el cual se aplica Y. Rivas sobre el cuento de Caperucita Roja (cuento ropálico, es decir, escrito de forma romboide) en Los cuentos del espejo, sorprende a primera vista, mientras que el trabajo de abstrac- 
ción implicado en el juego gráfico de W. Lavater (Paris, Maeght, 1968) obliga al lector a la reconstrucción de una Caperucita Roja personal.

Los dos textos más conocidos, escritos a partir de cuentos populares y que parecen constituir la trama de base (hipotexto) de los álbumes considerados más arriba, son por supuesto, $\mathrm{Ca}$ perucita Roja de Ch. Perrault, 1697, y Caperucita Roja de los hermanos Grimm (Contes, traducción, 1973, Paris, Gallimard, coll. Folio junior y Gründ). Los Grimm habían tomado, sin mucho humor, un esquema estructural complejo de una "acción contraria" (Caperucita y su abuela se salen del vientre del lobo), a diferencia de Perrault que termina su escrito en función de la "mala acción” (la Caperucita que es devorada).

Para terminar mencionaremos el más famoso, el más complejo y el más sutil sin duda de los juegos narrativos inspirados por las dos Caperucitas Rojas precedentes, Le Loup de los Contes du Chat Perché de M. Aymé, donde los personajes confiesan sufrir las consecuencias de una reputación generada en la primera historia. Es uno de los mecanismos del humor de Aymé que retoma, de alguna manera, la tradición de Perrault.

\section{Las variantes sobre un mismo esquema estructural}

Estas variantes señalan otra categoría en la clasificación de las relaciones entre textos, distinta de la parodia e, igualmente, legitiman su agrupamiento y su confrontación. Tomamos aquí el ejemplo de Cendrillon (Cenicienta) cuya lectura fue organizada en una clase de Ciclo Medio 1 y $2^{5}$ a partir de talleres, cada uno encargado de leer y estudiar una de las variantes escogidas con la ayuda de consignas. La lista siguiente presenta la síntesis de la comparación final de estas lecturas. Las consignas condujeron a los alumnos a utilizar criterios mencionados verticalmente.

1. "La Cendrouse", Le Conte Populaire français, de P. Delarue et M. L. Ténèze (1977).

2. "Cendrillon", Cuentos de Charles Perrault $(1697,1939$, reed).

5 Corresponde a los grados cuarto y quinto de primaria en el sistema educativo colombiano.
3. "Baba Yaga" y "Wassilissa la Belle", Cuentos rusos, Afanassiev, edición rusa (1957).

4. "Cenicienta", Contes de J. W. Grimm (1976).

Al modelo de Cenicienta le subyace, por otra parte, la trama de varias novelas realistas, entre otras:

1. La maison des Petits Bonheurs (1939, 1970).

2. Le Fauteuil de Grand'Mère (1980).

\section{"A la manera de Andersen"}

El cuento "moderno" que se considera aho$\mathrm{ra}$, se inscribe en otra perspectiva que podría denominarse "a la manera de Andersen". Se trata de una forma de reverencia humorística trabajada por M. Nickly y J. Claverie, el autor de $L a$ Princesse sur un pois, quien nos anuncia una continuación del cuento de Andersen (1937).

M. Nickly y J. Claverie, La Princesse sur une noix, ou le mariage problématique de la Princesse au pois (1981).

La ligereza de las transformaciones sufridas por la primera historia, la similitud del tono entre las dos obras, nos invitan a tomar el álbum de Nickly y de Claverie más como un pastiche humorístico, aunque no despojado de ternura, que como una parodia.

\section{Aspectos comunes entre los dos cuentos}

El boceto de la historia:

-Un príncipe parte en busca de una princesa para desposarla.

-Un obstáculo se opone al éxito de su búsqueda: la duda aparece en el príncipe.

-El obstáculo es superado.

-Matrimonio entre el príncipe y la princesa.

Algunas propiedades del objeto mágico:

-Forma redonda de la alverja y la nuez.

-Vegetales secos, en medio del invierno como principio de vida (alimento de los hombres, posibilidad de germinación y por lo tanto de reproducción). 


\section{Aspectos diferenciadores}

Desplazamiento del objeto de duda:

- En Andersen, el príncipe quiere estar seguro de que "ella es la verdadera princesa" a quien él desea.

- En Nickly, es más bien otro asunto como: "es posible encontrar una princesa con algún defecto ya que la perfección es incómoda" y, por tanto, modificación leve del objeto de búsqueda: princesa con pequeña imperfección.

\section{Consecuencia:}

- Debilitamiento de la prueba de verdad, la reina de la alverja, ex princesa de la alverja, más tolerante que su suegra, disminuye el número de colchones y modifica el objeto mágico: una nuez en lugar de una alverja, con una talla y consistencia diferentes, más fácil de sentir a través de los colchones...

\section{Función del objeto mágico}

La presencia de la alverja está encargada de develar la delicadeza extrema de una verdadera princesa, mientras que la nuez, por el contrario, revelará la pesadez de su sueño.

El juego de equivalencias y de diferencias sobre las propiedades de objetos tan consistentes como una alverja o una nuez, el reenvío constante del uno al otro, en la imagen de Claverie, son propicios para provocar humor, en tanto principio unificador del texto de Nickly y de la ilustración de Claverie. Más aún, la selección de textos y gráficos de los autores permiten al lector un juego suplementario de distanciamiento en relación con el texto ya humorístico del cuento de Andersen, invocado desde el preámbulo.

\section{Max, Zefir y los otros...}

Otra forma de relacionar dos obras para justificar su posible reagrupamiento nos la proporciona el resurgimiento, tal vez inconsciente, de motivos o elementos diversos en la segunda obra, de tonalidad bastante diferente a la primera.
Una rápida confrontación entre Vacances de Zéphir, por J. de Brunhoff (1983) y Max et les Maximonstres, por M. Sendak (1963, 1967), revela algunas semejanzas entre los dos libros. Estas tienen que ver con la organización del relato, la presencia de ciertos motivos y de aspectos del tratamiento gráfico. Una maravillosa aventura le sucede al pequeño mico Zefir durante unas vacaciones que parecen ordinarias. Ella ocurre de noche, en su alcoba, y por advertencia de un ruiseñor que lo despierta. Para Max, un sueño se inserta en el relato de un castigo banal: "está acostado en su cama, sin haber comido nada. Esa noche, un bosque crece en la alcoba de Max".

En el momento de la narración, Sendak encuentra los colores ocres de Brunhoff, finamente delineados por breves trazos negros, con dominancia de azules, café y verde, más sombrío este último.

El motivo de la ventana abierta sobre una noche empalidecida por la luna (que los ilustradores ubican en lo alto del marco, con el mono Zefir recostado en la ventana en Brunhoff, y Max en la alcoba, de espaldas a la ventana, en Sendak) subraya más la atención en Sendak que lo retoma en la página siguiente y al final. Igualmente, el mar es un elemento en el cual se embarcan los dos héroes para realizar el periplo de la búsqueda. Podemos acercar el carácter más bien bonachón y ridículo de Polomoche y de los Gogotes al de los Maximonstruos que se balancean por momentos en las ramas de los árboles como en los monos de Vacaciones de Zefir. En fin, la apoteosis de los dos héroes, pequeñas criaturas inofensivas, se presenta de manera análoga: se vuelven maestros de los monstruos al divertirlos por las Bacanales incansables que literalmente los hacen caer de sueño ${ }^{6}$.

\footnotetext{
6 Entre la multitud de textos que se hacen eco y justifican un eventual agrupamiento de los mismos, citamos solamente L'Arbre qui chante (Clavel y Lorin, 1967) y Le Luthier de Venise (Clément y Clément, 1988), por el tema del árbol muerto que revive en un violín; Le Château des enfants volés (Gripe, 1975) y Les voyageurs sans souci (Lerme-Walter, 1970), por el personaje de la ciudad mágica y los elementos temáticos; Alice aux Pays des Merveilles (Carroll, 1968, y otras...), y La petite Géante (Dumas, 1977), por las metamorfosis, el universo y algunos encuentros del periplo onírico de los personajes.
} 


\begin{tabular}{|c|c|c|c|c|c|}
\hline $\begin{array}{l}\text { Criterios } \\
\text { considerados / } \\
\text { Textos }\end{array}$ & $\begin{array}{l}\text { La Cenizosa } \\
\text { (cuento -tipo } \\
510 \mathrm{~A} \text { ) }\end{array}$ & $\begin{array}{l}\text { Cenicienta } \\
\text { (Perrault) }\end{array}$ & Baba-Yaga & $\begin{array}{l}\text { Wassilissa-la- } \\
\text { Bella }\end{array}$ & $\begin{array}{l}\text { Cenicienta } \\
\text { (Grimm) }\end{array}$ \\
\hline Situación inicial & $\begin{array}{l}\text { Una hermana } \\
\text { menor } \\
\text { despreciada } \\
\text { solitaria } \\
\text { inicial }\end{array}$ & $\begin{array}{l}\text { Una huérfana } \\
\text { solitaria }\end{array}$ & $\begin{array}{l}\text { Una huérfana } \\
\text { solitaria }\end{array}$ & $\begin{array}{l}\text { Una hermana } \\
\text { menor } \\
\text { Una huérfana } \\
\text { solitaria }\end{array}$ & $\begin{array}{l}\text { Una huérfana } \\
\text { solitaria }\end{array}$ \\
\hline Personajes y roles & & & & & \\
\hline Víctima: & Cenizosa & Cenicienta & La joven & Wassilissa & Cenicienta \\
\hline Oponentes: & Las hermanas & 0 & 0 & 0 & 0 \\
\hline Agresor: & 0 & La madrastra & La madrastra & $\begin{array}{l}\text { La madrastra } \\
\text { y sus hijas }\end{array}$ & La madrastra \\
\hline Héroe que va en busca: & El príncipe & El príncipe & La joven & $\begin{array}{l}\text { Wassilissa / } \\
\text { El príncipe }\end{array}$ & El príncipe \\
\hline Falso-héroe: & 0 & Las hermanas & $\begin{array}{l}\text { La hija de la } \\
\text { madrastra }\end{array}$ & 0 & $\begin{array}{l}\text { Las dos } \\
\text { hermanas }\end{array}$ \\
\hline Mandatario: & 0 & 0 & El padre & El padre & 0 \\
\hline Donante: & El padre & $\begin{array}{l}\text { El hada } \\
\text { madrina }\end{array}$ & Baba-Yaga & $\begin{array}{l}\text { la madre y } \\
\text { Baba-Yaga }\end{array}$ & $\begin{array}{l}\text { La madre, el } \\
\text { padre }\end{array}$ \\
\hline Objetos mágicos & La avellana & $\begin{array}{l}\text { La zapatilla } \\
\text { de cristal }\end{array}$ & Los ratones & $\begin{array}{l}\text { La bendición } \\
\text { maternal } \\
\text { simbolizada } \\
\text { por la muñeca }\end{array}$ & $\begin{array}{l}\text { La bendición } \\
\text { maternal y } \\
\text { la rama de } \\
\text { avellano dada } \\
\text { por el padre: } \\
\text { el avellano, el } \\
\text { pájaro blanco } \\
\text { y los otros } \\
\text { pájaros. }\end{array}$ \\
\hline $\begin{array}{l}\text { Fechoría / } \\
\text { Ausencia }\end{array}$ & $\begin{array}{l}\text { La joven no se } \\
\text { divierte }\end{array}$ & $\begin{array}{l}\text { Desprecio de } \\
\text { la madrastra } \\
\text { Trabajos } \\
\text { impuestos }\end{array}$ & $\begin{array}{l}\text { Odio de la } \\
\text { madrastra }\end{array}$ & $\begin{array}{l}\text { Odio de la } \\
\text { madrastra: } \\
\text { - trabajos } \\
\text { impuestos } \\
\text { - Wassilissa } \\
\text { es atrapada } \\
\text { y enviada a } \\
\text { donde la bruja }\end{array}$ & $\begin{array}{l}\text { Odio de la } \\
\text { madrastra } \\
\text { trabajos } \\
\text { degradantes } \\
\text { impuestos }\end{array}$ \\
\hline
\end{tabular}




\begin{tabular}{|c|c|c|c|c|c|}
\hline Pruebas & $\begin{array}{l}\text { 1) Prueba del } \\
\text { donante } \\
\text { 2) Su reloj } \\
\text { en la misa (2 } \\
\text { veces) } \\
\text { 3) Tarea } \\
\text { difícil: } \\
\text { poner la } \\
\text { zapatilla, } \\
\text { cumplida. }\end{array}$ & $\begin{array}{l}\text { 1) Prueba del } \\
\text { donante } \\
\text { 2) El baile: } \\
\text { dos veces. } \\
\text { segunda vez: } \\
\text { pérdida } \\
\text { 3) Tarea } \\
\text { difícil: } \\
\text { poner la } \\
\text { zapatilla, } \\
\text { cumplida }\end{array}$ & $\begin{array}{l}\text { 1) Donde } \\
\text { Baba-Yaga } \\
=2 \text { series de } \\
\text { trabajos } \\
\text { 2) Regreso de } \\
\text { la joven a su } \\
\text { casa. El objeto } \\
\text { mágico } \\
\text { 3) Castigo de } \\
\text { la madrastra } \\
\text { por la muerte } \\
\text { de su hija }\end{array}$ & $\begin{array}{l}\text { 1) En casa de } \\
\text { la madrastra: } \\
\text { - Varias series } \\
\text { de trabajos, } \\
\text { ayuda del } \\
\text { donante } \\
\text {-Persecución } \\
\text { en el bosque } \\
\text { 2) En casa de } \\
\text { Baba-Yaga: } \\
\text { - Varias series } \\
\text { de trabajos } \\
\text { - Preguntas } \\
\text { sobre los } \\
\text { caballeros } \\
\text { 3) Tareas } \\
\text { difíciles, } \\
\text { realizadas }\end{array}$ & $\begin{array}{l}\text { 1) En casa de } \\
\text { la madrastra: } \\
\text { - Dos series } \\
\text { de trabajos: } \\
\text { selección de } \\
\text { lentejas } \\
\text { - Prohibición } \\
\text { de ir al baile. } \\
\text { Ayuda del } \\
\text { donante } \\
\text { 2) el baile: tres } \\
\text { veces, regreso } \\
\text { 3) Prueba de } \\
\text { la zapatilla: } \\
\text { tarea difícil de } \\
\text { cumplir }\end{array}$ \\
\hline Situación final & $\begin{array}{l}\text { Cenizosa } \\
\text { reconocida } \\
\text { como la } \\
\text { más bella. } \\
\text { Matrimonio } \\
\text { con el hijo del } \\
\text { rey }\end{array}$ & $\begin{array}{l}\text { Cenicienta } \\
\text { reconocida } \\
\text { como la } \\
\text { más bella. } \\
\text { Matrimonio } \\
\text { con el hijo del } \\
\text { rey }\end{array}$ & $\begin{array}{l}\text { Jovencita: } \\
\text { - libre } \\
\text { (liberada de la } \\
\text { madrastra) - } \\
\text { rica. }\end{array}$ & $\begin{array}{l}\text { Wassilissa: } \\
\text { liberada de } \\
\text { la madrastra, } \\
\text { casada, reina } \\
\text { ociosa, feliz. }\end{array}$ & $\begin{array}{l}\text { Cenicienta: } \\
\text { bella, } \\
\text { casada con } \\
\text { el príncipe, } \\
\text { ociosa, feliz. }\end{array}$ \\
\hline
\end{tabular}

\section{Los mil y un círculos del agrupamiento de textos (una experiencia en los ciclos de ce2-cm1-cm2) ${ }^{7}$}

\section{Serge Martin}

Je tourne les yeux vers les écoles d'Europe. J'y vois le métier de Raison dont la trame s'enrage, lavée aux aubes de Newton. Noire la toile qui, en épaisses volutes, recouvre les Nations : implacable de travail de ces roues sans nombre, l'une à l'autre engrenées, qui se contraignent à bouger...

7 Como se anotó, estos ciclos se corresponden con los cursos tercero, cuarto y quinto de básica primaria en $\mathrm{Co}^{-}$ lombia.
"Vuelvo los ojos hacia las escuelas de Europa. Allí veo el papel de la Razón cuya trama rabiosa es lavada por las albas de Newton. Negra la tela que en espesas volutas recorre las naciones: implacable por el trabajo de esas ruedas sin nombre, la una y la otra, engranadas, que se obligan a moverse...”

William Blake

\section{Desde dónde "se habla" en el agrupamiento de textos}

El pedagogo que agrupa los textos es normalmente consciente de sus elecciones. "Mi" agrupamiento de Textos tuvo su pre-texto (s) en el estudio de las locuciones temporales que es- 
tructuran los textos y señalan a su lector el anclaje de los acontecimientos narrativos en el (los) tiempo de la ficción (¡estudio más que necesario para los alumnos del ciclo de las profundizaciones!). En su origen escogí un texto corto, un "poema" (doc. 1) que mucho más tarde concentrará "los placeres de la sorpresa y las alegrías de las travesuras" (según la feliz expresión de Jean Perrot se trata de "vías" ofrecidas por la literatura para jóvenes) cuando una clase y su profesor trabajan en "agrupamiento de textos".

\section{Documento 1.}

\section{EL COMIENZO DEL FIN}

Un diitia naciò la aurorita, la microaurora

Luego fue el sol bien explayado sobre su tostada

Termina por extenderla, te golpea con el blanco de las nubes,

y la forma de las bumaredas de la noche

y la tarde muere, la muy pequeñita crepe, la crepúscula.

Raymond Queneau ${ }^{8}$

\section{El agrupamiento de textos no puede ser ignorado ya que tiene su encanto...}

La comparación entre el comienzo y el final de un relato se ha vuelto una práctica generalizada en nuestras clases. Los comienzos de novelas (cfr. J. Verrier, éd. Bertrand Lacoste, coll. "Parcours de lecture"), el juego de las diferencias podría constituir un agrupamiento de textos aconsejable al final de la primaria. Júzguenlo: un álbum como Un jornada de perro (coll. Gobelune, Hachette, 1981) trata simplemente de jugar a la búsqueda de las modificaciones entre dos imágenes (los grabados iniciales y finales) con el mismo decorado: la entrada al apartamento; Cyrus,

8 Texto original: Le début la fin Au petit jour naît la petite aube, la microaube puis c'est le soleil bien à plat sur sa tartine il finit par l'étaler, on te bat avec le blanc des nuages, et la forme des fumées de la nuit et le soir meurt, la toute petite crêpe, la crépuscule. el perro, agazapado en la misma posición a la izquierda; el padre, la madre y Arthur, el hijo, salen y luego entran. Esta simetría perfecta se ve en extremo perturbada por un sombrero de fiesta-situado en el rincón a la derecha del último grabado, en consecuencia, jal extremo final del álbum! - dejado allá, que Arturo señala con un "oh", la palabra final. E1 lector sabe que Cyrus ha pasado un día loco señalado como "esa mañana allá", "nueve horas treinta", "dos horas menos cinco", "y después" (tres veces), "entonces”, "hacia las cinco"... el muro de la clase se cubre ahora de fotocopias de las primeras y de los últimos grabados de álbumes rebuscados en las tiras cómicas que ofrecen tales juegos de diferencias. ¡Me parece que el agrupamiento de textos juega sobre lo parecido!

\section{Documento 2:}

A modo ilustrativo presentamos tres álbumes que comienzan y finalizan en la cama (!) contrario a otros que oponen paralelamente dos grabados similares al comienzo y al final.

Merce Mayer, Il y a un alligator sous mon lit (1988: 4-5 y 30-31). Habría tres diferencias: la tabla en el piso, el héroe en la cama, la luz apagada.

Maurice Sendak, Max et les maximonstres (1967 : 9 y 39). Max se quita su disfraz; la cena está sobre la mesa: ¡un año de castigo!

Pierre Le-Tan, Voyage au pôle Nord (1988: 7 y 27). Observar bien los dos cuadros en el muro: el libro desaparece sobre la cama, la cabeza de la madre aparece a la derecha.

\section{Cuando es necesario volver al agrupamiento de textos al revés...}

Un álbum nos dice que es diferente cuando el comienzo y el final son casi la misma cosa, o al menos la misma página. Aller et retour de Ann Jonas (1983), comienza y termina en efecto sobre el mismo grabado: las 16 páginas dobles ofrecen 32 "células textuales", 16 en un sentido sobre la página par, abajo a la izquierda, y 16 en el otro sentido sobre la página impar arriba a la derecha, es decir, abajo a la izquierda cuando giramos el libro, descubriendo la sutil alianza de dos imágenes: ¡metamorfosis de una inversión! 
"Las locuciones temporales", recuerda el pedagogo concienzudo, “y”, “y entonces”... harían concluir sobre su pobreza si el álbum no ofreciera la sorpresa de lecturas encontradas que giran en redondo como la tierra... (¿como el tiempo?).

\section{Cuando los agrupamientos de textos tienen visiones...}

El aprendizaje de la lectura de textos largos es una preocupación compartida por los maestros de tercero y cuarto a lo cual debería responder el agrupamiento de textos.
El maestro había previsto un salto de un texto largo: las 16 páginas de una novela de Le Clézio, La roue d'eau (1978). Sin consigna, los alumnos parten hacia la búsqueda de locuciones temporales pero pronto un grupo se autorizará a escribir los lugares del relato porque "es como en Ida y regreso: ¡Juba sale de la casa y vuelve!" Después, una mirada a las tiras cómicas nos llevará a los dos álbumes de Mitsumasa Anno, La terre est un cadran solaire y Comment la terre est devenue ronde ${ }^{9}$, un grupo de alumnos se lanzará a una escritura circular de locuciones temporales de textos de Le Clézio.

Documento 3:

\begin{tabular}{|c|c|c|}
\hline \multicolumn{3}{|c|}{ La rueda de agua. De J. M. G. Le Clézio } \\
\hline $\begin{array}{l}\text { Página en la edición } \\
\text { folio }\end{array}$ & $\begin{array}{l}\text { Indicaciones temporales esen- } \\
\text { ciales: }\end{array}$ & $\begin{array}{l}\text { Indicaciones temporales esen- } \\
\text { ciales: }\end{array}$ \\
\hline \multicolumn{3}{|l|}{$\mathrm{El} \mathrm{sol...}$} \\
\hline \multirow[t]{2}{*}{149} & $\begin{array}{l}\text { - El sol todavía no se había le- } \\
\text { vantado sobre el río }[\ldots]\end{array}$ & - casa \\
\hline & - La noche es gris y fría. & - sendero \\
\hline \multirow[t]{2}{*}{150} & $\begin{array}{l}\text { - Pronto el día va a aparecer }[\ldots] \\
\text { la llegada de la luz }[. . .]\end{array}$ & \\
\hline & - La noche se abre $[\ldots]$ & \\
\hline 151 & & - sobre la otra vertiente \\
\hline 152 & - Cuando al fin sale el sol $[\ldots]$ & $\begin{array}{l}\text { - el pozo } \\
\text { - la noria }\end{array}$ \\
\hline 153 & $\begin{array}{l}\text { - El sol recalienta }[\ldots] \\
\text { La luz del día vibra }[\ldots]\end{array}$ & - al borde del pozo \\
\hline 154 & $\begin{array}{l}\text { - El sol asciende sin prisa en el } \\
\text { cielo }[\ldots]\end{array}$ & \\
\hline
\end{tabular}

9 Una mirada rápida de este álbum ofrece la sorpresa de ver la tierra plana redondearse hasta volverse un globo. Los 20 grabados de esta metamorfosis son como la alegoría del paso de una lectura lineal a una lectura en círculos... En los "comentarios del autor", M. Anno afirma: "le hubiera podido dar a mi libro un título más largo. Lo hubiera podido llamar: Cómo el pueblo que vivía en la era de Tolomeo veía su universo (...)". Un alumno señalaría este pasaje y lo relacionaría con los pasajes de J. M. G. Le Clézio, "Se enseñará la ciencia de los astros [...]” (p. 160), y "Mi hijo Tolomeo va a nacer” (p. 161). Los diccionarios distinguirán y afinarán la comprensión, permitirán percibir la analogía de Yol con Alejandría... 
Tal vez es el mismo movimiento que conlleva el astro en el centro del cielo, mientras que los bueyes avanzan pesadamente a lo largo del camino circular [...] Juba [...] ve el lento movimiento circular que traza sus estelas fosforescentes, ve las esferas transparentes, los engranajes de la luz en el espacio.

\begin{tabular}{|l|l|l|}
\hline 155 & $\begin{array}{l}\text { - Después, mientras que el sol } \\
\text { asciende lentamente [...] }\end{array}$ & $\begin{array}{l}\text { sobre las alas de un buitre } \\
\text { blanco }\end{array}$ \\
\hline 156 & $\bullet$ La luz es grande, el cielo abierto. & \\
\hline
\end{tabular}

Solo hay agua, tierra, cielo, planos móviles que pasan y se cruzan, cada elemento es parecido a una rueda dentada mordiendo en un engranaje.

\begin{tabular}{|l|l|l|}
\hline & $\begin{array}{l}\bullet[\ldots] \text { cuando la luz del sol es } \\
\text { muy fuerte }[\ldots]\end{array}$ & $\bullet$ Yol aparece fuerte $[\ldots]$ \\
\hline & $\begin{array}{l}\text { • ahora }[\ldots] \text { cuando el sol está } \\
\text { más alto en el cielo }[\ldots]\end{array}$ & \\
\hline
\end{tabular}

[...] en la música lenta de las ruedas, en la luz deslumbrante [...]

\begin{tabular}{|l|l|l|}
\hline 157 & $\begin{array}{l}\text { - la luz del sol ilumina el cuerpo } \\
\text { de Juba }[\ldots]\end{array}$ & $\bullet$ Yol aparece fuerte $[\ldots]$ \\
\hline 158 & $\bullet$ el templo de Diana & \\
\hline
\end{tabular}

El lento movimiento circular traza la línea pura del horizonte $[\ldots]$

$159 \quad$ En el cielo, el sol desciende $[\ldots]$ poco a poco, sobre su camino

- en lo alto de los peldaños del circular $[\ldots]$ templo

Pero el movimiento lento de las ruedas continúa [...]

\begin{tabular}{|l|l|l|}
\hline 160 & $\bullet[\ldots]$ la luz de la tarde $[\ldots]$ & \\
\hline 161 & $\begin{array}{l}\bullet \text { Las sombras se agrandan sobre } \\
\text { la tierra, mientras que el sol } \\
\text { desciende poco a poco hacia el } \\
\text { oeste }[\ldots]\end{array}$ & $\begin{array}{l}\bullet \text { las ruinas de YOL } \\
\bullet \text { un cementerio }[\ldots] \text { al fondo } \\
\text { del mar }\end{array}$ \\
\hline 162 & $\begin{array}{l}\text { - La luna creciente ha aparecido } \\
{[\ldots]} \\
\bullet \text { La noche se eleva hacia el otro } \\
\text { extremo de la tierra }[\ldots]\end{array}$ & \\
\hline 164 & $\begin{array}{l}\bullet \text { Pronto el día va a aparecer }[\ldots] \\
\text { la llegada de la luz }[\ldots]\end{array}$ & $\bullet$ hacia las casas \\
\hline
\end{tabular}


Tal vez mañana, cuando las grandes ruedas de madera comiencen a girar de nuevo [...] sobre su camino circular, entonces la ciudad aparecerá de nuevo, muy blanca, temblorosa, irreal, ¿como los reflejos del sol? Juba gira un poco sobre sí mismo [...] camina hacia las casas donde los vivos lo esperan.

\section{Cuando el agrupamiento de textos se vuelve la rueda de la fortuna...}

La escritura de "fichas técnicas" permitirá relacionar la ficción y los documentos, pasando de la explicación del texto o de términos (noria, madero, timón, yugo, engranaje, brocal, acequia...). La escritura de "biografías históricas" cruzará los biografemas de la ficción y los documentales evitando volver transparente un texto que afecta la visión, la iniciación y no explicación (Juba, Himyar, Tolomeo, Cleopatra, Selene...).

En fin, dos actividades de escritura de ficción intentarán un último turno del agrupamiento de textos:

1. La escritura del relato sobre el boceto de las locuciones temporales tomadas en uno de los textos del agrupamiento, algunos alumnos llegarán a retomar aquellos del texto de Le Clézio.

2. La escritura de una "antología" de anotaciones (en negrilla en el documento 3) sobre el movimiento circular en la novela de Le Clézio. Escritura que por supuesto deberá hacer girar los engranajes sobre los dientes de las letras y donde el espacio de la página reconstituirá el palacio de Circe (evocado por una lectura del maestro). Este tipo de notaciones resaltadas en el texto constituirá un arte poético del mismo estilo que el poema de Queneau.

\section{Cuando el agrupamiento de textos puede ir sobre ruedas...}

Al fin de cuentas, solamente cuatro textos estuvieron verdaderamente en el programa del agrupamiento de textos. En realidad, los recorridos fueron muy diversos para cada alumno. Dos certezas llevan al maestro a alabar las virtudes de recurso:

- La cantidad de lectura de los alumnos crece de manera casi exponencial y no es al azar: pasar a la lectura "larga" antes de entrar a la secundaria exigirá este hábito de senderos cruzados que permite el agrupamiento de textos.

- La calidad del cuestionamiento -a veces sin respuesta- de los alumnos que ya no dirán más "microbio" sin dejar de ver despuntar el día, ni dirán "crepúsculo" sin pensar en nuestra pequeñez.

El lector habrá comprendido que el alumno ha sido al menos sensibilizado hacia lo que estructura, no solamente lo cotidiano de cada ser humano $(i)$ sino también la imaginación de los más grandes poetas desde "el alba" de los trovadores hasta la pregunta: "¿Pero, qué es entonces para ti este día recién nacido?” formulada por J. Roubaud en La Pluralité des mondes de Lewis (1991). Alba... y crepúsculo (Baudelaire, Wagner...), son lugares por excelencia del impulso metafórico del lenguaje. ¡Con el extrañamiento que se narra se podrá transformar, entonces, un pobre agrupamiento de textos en un relato mítico!

\section{Referencias bibliográficas}

Afanassiev (1957). "Baba Yaga" y "Wassilissa la Belle”. En Cuentos rusos. Edición rusa.

Andersen, H. C. (1937). Cuentos (Dk. 1835 à 1874, traducción). Mercure de France, École des loisirs, coll. Neuf en poche, 3 tomos.

Boucher, J. (1989). Les Rêrves de Noé: Escale à New-York. Paris: Nathan.

Carroll, L. (1968). Alice aux Pays des Merveilles. Flammarion.

Clavel, B. y Ph. Lorin (1967). LArbre qui chante. Paris: Messidor/La Farandole.

Clavigny, G. (1867-1946). L'Arche de Noé, ilustración de O'Galop. Paris: Albin Michel, s.d.

Clément, C. y F. Clément (1988). Le Luthier de Venise. Paris: Pastel. 
De Brunhoff, J. (1936). Vacances de Zéphir. Paris: Hachette (reedición École des loisirs, 1983).

Delarue P. y M. L. Ténèze (1977). "La Cendrouse". En Le Conte Populaire français. Paris: Maisonneuve et Larose, tomo II.

Dumas, Ph. (1977). La petite Géante. Paris: École des loisirs.

Genette, G. (1982). Palimpsestes. Paris: Seuil, Poétique.

Greenaway, K. (1886). De A Apple pie. Londres: Evans (reedición Castle Books, 1979, y Paris: Hachette, 1986).

Grimm, J. W. (1973). "Petit Chaperon Rouge". En Contes. Paris: Gallimard, coll. Folio junior y Gründ.

Grimm, J. W. (1976). “Cendrillon”. En Contes du Grimm, 1812-1822. Paris: Gallimard, coll. Folio.

Gripe, M. (1975). Le Château des enfants volés, trad. suca. Hatier, L'amitié.

Herman, C. (1980). Le Fauteuil de Grand'Mère. Paris: Flammarion, Castor poche.

Roubaud, J. (1991). La Pluralité des mondes de Lewis. Paris: Gallimard.

Jonas, A. (1983). Aller et retour. L'École des loisirs.

Le Clézio, J. M. G. (1978). “La roue d'eau”. En Mondo et autres histoires. Paris: Folio-Gallimard.

Lerme-Walter, M. (1970). Les voyageurs sans souci. Paris: Nathan.

Le-Tan, P. (1988). Voyage au pôle Nord. Pastel, École des loisirs.

Marshell, J. (1989). Petit Chaperon Rouge. Paris: Kaléidoscope.

Mayer, M. (1988). Il y a un alligator sous mon lit. Paris: Pastel, École des loisirs.
Moissard, B. (1977, 1989). "Petit Chaperon Bleu Marine”. En Contes à l'envers, ilustrado en blanco y negro por P. Dumas. Paris: École des loisirs, Neuf en poche.

Nickly, M. y J. Claverie (1981). La Princesse sur une noix, ou le mariage problématique de la Princesse au pois. Paris: Nord-Sud.

Parmegiani, C. A. (1989). Les Petits Français illustrés. Paris: Cercle de la Librairie.

Perrault, Ch. (1939, reed.). "Cendrillon". En Contes du Perrault [1697]. Paris: Larousse Classiques.

Reuter, Y. (1988). L'importance du personnage. En Pratiques, 60, CRDP de Clermont-Ferrand.

Reuter, Y. (1991). Parcours d'orientation dans le livre de C. Tauveron. CRDP de ClermontFerrand.

Reuter, Y. (dir.) (1987). Le personnage dans les récits. En Cabier de recherche didactique du français, 2, CRDP de Clermont-Ferrand.

Rivas, Y. (s. f.). Los cuentos del espejo. Paris: École des loisirs, Neuf en poche.

Rosenstielh, A. (1977). Drôle d'alphabet, ou les aventura d'une tarte aux pommes. Paris: Larousse.

Ross, T. (1980). Caperucita Roja. Paris: Gallimard, Folio benjamín.

Sendak, M. (1967). Max et les Maximonstres. Paris: Delpire, École des loisirs.

Solotareff, G. y Nadja (1989). Petit Chaperon Vert. Paris: École des loisirs, Renardeau.

Spier, P. (1978). L'Arche de Noé. Paris, École des loisirs.

Vivier, C. [1939] (1970). La maison des Petits Bonheurs. Paris: La Farandole. 